Article

\title{
Effect of Magnesium Ion Concentration on the Scale Inhibition of Heat Exchanger in Circulating Cooling Water under Alternating Electric Field
}

\author{
Zhihao Zhang, Yun Jia and Judong Zhao* \\ College of Science, Inner Mongolia University of Technology, Hohhot 010051, China; zzh2965@163.com (Z.Z.); \\ yunbao2004haijun@163.com (Y.J.) \\ * Correspondence: jdzhao@imut.edu.cn; Tel.: +86-133-4713-8076
}

Received: 14 July 2020; Accepted: 6 August 2020; Published: 8 August 2020

\begin{abstract}
This work investigated the effect of magnesium ion concentration on the formation of mineral scale in circulating cooling water under alternating electric field treatment (AEFT) by using a self-made power plant circulating cooling water simulator. In this experiment, the circulating cooling water used was artificial hard water. Three experimental groups with different magnesium ion concentrations and three corresponding control groups were studied. Scale inhibition rate, fouling resistance, calcium ion concentration, crystal phase, and crystal morphology were discussed. Results showed that $4 \mathrm{mmol} / \mathrm{L}$ magnesium chloride promoted the formation of scale on the copper tube wall, and the average scale inhibition rate was $-107.86 \%$. When the magnesium chloride concentration was $6 \mathrm{mmol} / \mathrm{L}$, the situation was reversed, and the average scale inhibition rate reached $59.11 \%$. The changes in calcium ion concentration supported the scale inhibition rate. Scanning electron microscope (SEM) photos showed the change in the composition of calcium carbonate crystals. The results showed that the effect of AEFT on fouling resistance is nonlinearly related to the concentration of magnesium ions in circulating cooling water.
\end{abstract}

Keywords: alternating electric field; adherent scale; non-adherent scale; circulating cooling water; magnesium ion concentration; calcium carbonate

\section{Introduction}

The problems on production safety and equipment maintenance caused by calcium carbonate scale have becoming increasingly serious. Calcium carbonate is an inversely soluble salt [1], that is, its solubility decreases with increasing temperature. Calcium and carbonate ions in the circulating cooling water combine to form calcium carbonate scale and are deposited on the surface of heat exchangers. Calcium carbonate has a thermal conductivity of $2.9 \mathrm{~W} / \mathrm{mK}$, which is less than $1 \%$ of that for metal copper ( $401 \mathrm{~W} / \mathrm{mK})$ [2]. Therefore, the calcium carbonate deposited on the heat exchanger can remarkably reduce heat exchange efficiency, likewise reducing the operating efficiency of the equipment and increasing the operating cost [3-7]. The average annual cost of cleaning and maintaining industrial production equipment due to scale is billions of dollars [2,4]. Adding a $1 \mathrm{~mm}$-thick limestone deposit can double the power consumption of a power plant [2]. Therefore, inhibiting the formation and deposition of calcium carbonate scale is highly valuable.

Scale inhibition methods are mainly classified into chemical and physical techniques. The former generally has disadvantages, such as high cost and secondary pollution to the environment [2,6], whereas the latter is economic and environmentally friendly [1,2,6,8-11]. Hence, physical water treatments may replace chemical methods. The main physical scale inhibition techniques include the use of magnetic fields, electric fields, ultrasonic waves, and RF(Radio Frequency) electric fields [2,4,6,7,12,13]. Among 
them, the electromagnetic field method is particularly interesting. Calcite scaling was easily produced, and the fouling resistance decreased remarkably after high-frequency electric field treatment [2]. Piyadasa et al. [14] studied the pulsed electromagnetic field water treatment device and found its effect on the crystal morphology of calcium carbonate. Zhao et al. [6] reported that the grain size and the proportions of aragonite and calcite change under the action of high-voltage electric field and variable frequency magnetic field. Moreover, Kobe et al. [15] stated that the proportions of calcite and aragonite change after magnetic field treatment. After electromagnetic field treatment, calcium carbonate is found in bulk water rather than being attached to the wall of the heat exchanger $[3,8,11,16-18]$.

Magnesium ions affect the crystallization and growth of calcium carbonate [19-21]. Low concentrations of magnesium ions are easily incorporated into calcite, but high concentrations have an inhibitory effect on the formation of calcite [20]. Davis et al. [19] proposed that the combination of magnesium ions and calcium carbonate crystal lattice changes the equilibrium thermodynamic properties of the new growth surface and inhibits the growth of calcite. Zhang and Dawe [21] suggested that the inhibitory effect of magnesium ion on the calcite is due to the uneven distribution of magnesium ions on the surface of the calcite crystal, leading to the formation of a new crystal surface and the reduced new surface growth rate. However, studies on the effects of magnesium ions on calcium carbonate mostly focused on the formation of natural minerals. The mechanism of magnesium ions on the scale formation of calcium carbonate in heat exchangers is unclear.

Although many studies confirmed the scale inhibition effect of electromagnetic fields, some showed the effect of magnesium ions on the growth of calcium carbonate. Whether magnesium ions and electromagnetic fields have a synergistic relationship with scale inhibition remains unclear. In the present experiment, we added AR-grade(Analytical Reagent grade) magnesium chloride to distilled water to prepare circulating cooling water. The following three different circulating cooling waters were prepared: without magnesium chloride, with $4 \mathrm{mmol} / \mathrm{L}$ magnesium chloride, and with $6 \mathrm{mmol} / \mathrm{L}$ magnesium chloride. We investigated the effect of magnesium ion concentration on the scale inhibition rate in the heat exchanger under alternating electric field treatment (AEFT). Three experimental groups and three control groups were designed. Water sample was obtained every $2 \mathrm{~h}$. Fouling resistance, scale inhibition rate, and calcium ion concentration were analyzed, and the aragonite and calcite contents in the scale were measured by XRD. SEM was performed to determine the changes in the grain morphology and grain size of the calcium carbonate scale.

\section{Facility and Methods}

\subsection{Experimental Device and Operation Process}

As shown in Figure 1, circulating cooling water was drawn out of the water collecting tank by placing a water circulation pump into the circulation pipe and was then processed by the AEFT device to enter the counter flow heat exchanger. The circulating cooling water was sprayed into the cooling tower to dissipate heat and collected again in the water collecting tank to form a loop. The circulating water flow rate was set to $1000 \mathrm{~L} / \mathrm{h}$. Each set of experiments lasted $12 \mathrm{~h}$, and the water indicator was measured every $2 \mathrm{~h}$. 


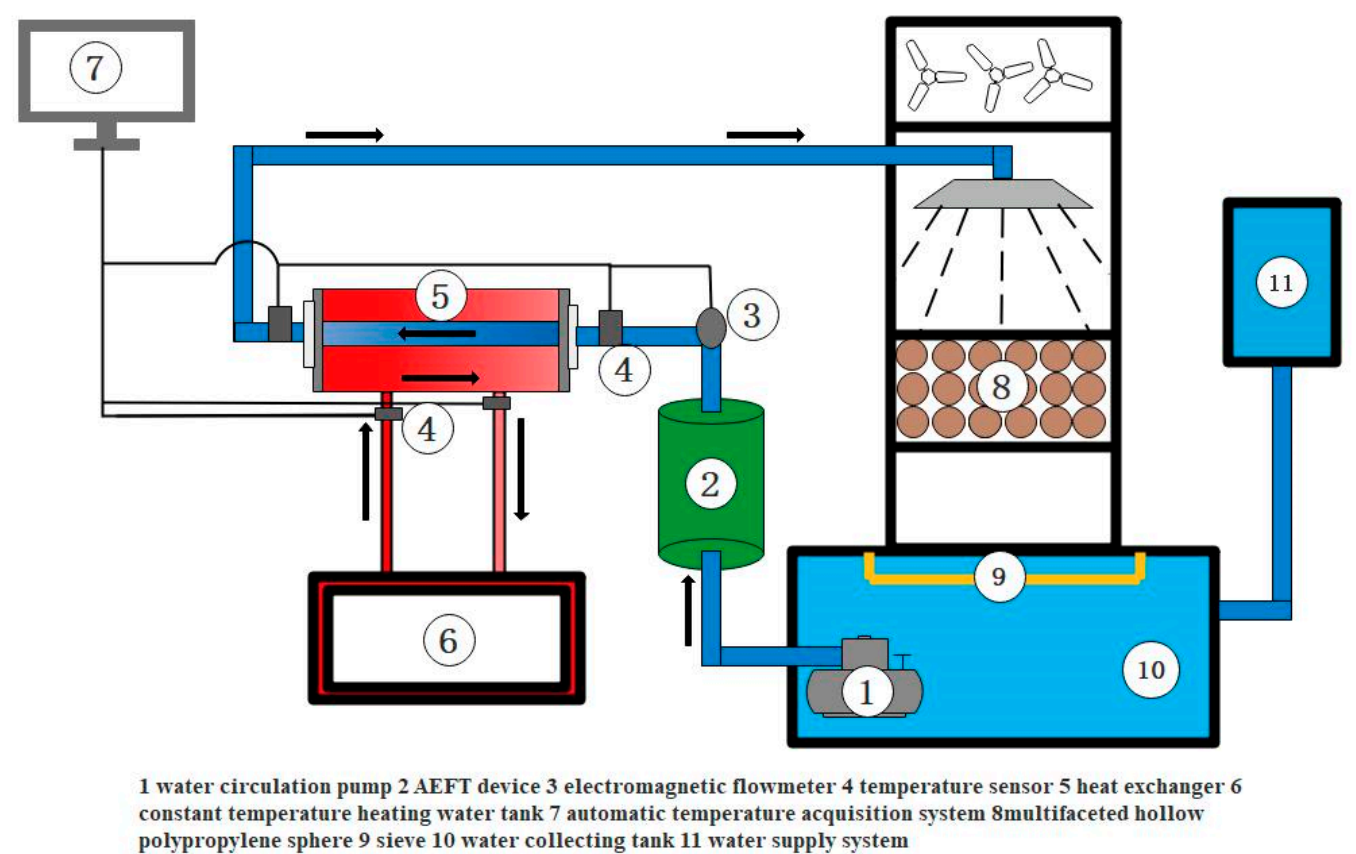

Figure 1. Alternating electric field treatment (AEFT) device and cycle process.

A heat exchanger is a double-layered casing structure. The circulating cooling water flows through the internal copper pipe, and the heated water flows outside the copper pipe. The inner wall of the copper tube must be smooth because the surface roughness increases the nucleation site and the fouling resistance [22]. The inner diameter and thickness of the copper tube were 22.5 and $2.5 \mathrm{~mm}$, respectively. Calcium carbonate scale was formed and deposited on the inner surface of the copper tube. PT100-type temperature sensor was installed in the inlet and outlet of the heated water and circulating cooling water, respectively. A computer recorded the temperature of each inlet and outlet every $10 \mathrm{~min}$. In the experiment, the temperature of the circulating cooling water was controlled at $32{ }^{\circ} \mathrm{C} \pm 2{ }^{\circ} \mathrm{C}$, and that of the heating water was controlled at $90{ }^{\circ} \mathrm{C} \pm 4{ }^{\circ} \mathrm{C}$.

As the experiment progressed, the amount of calcium ions and carbonate ions decreased due to the formation and precipitation of calcium carbonate. Hence, $\mathrm{CaCl}_{2}$ and $\mathrm{NaHCO}_{3}$ were supplemented at flow rates of 1.2 and $1.5 \mathrm{mmol} / \mathrm{L} \cdot \mathrm{h}$, respectively, to maintain the calcium ion concentration and the alkalinity of the circulating cooling water.

\subsection{Alternating Electric Field-Generating Device}

The alternating electric field-generating device is shown in Figure 2.

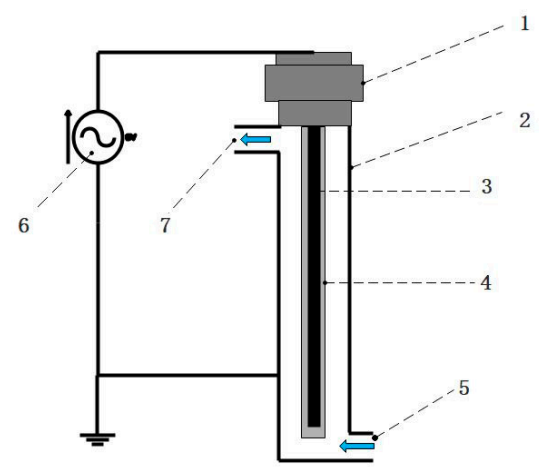

1 ion bar 2 negative metal tube 3 anode in the center of the ion bar 4 PTFE insulation 5 water inlet $64 \mathrm{kV}, 50 \mathrm{~Hz} \mathrm{AC}$ power supply 7 water outlet

Figure 2. AEFT device. 
The circulating cooling water enters from the lower inlet, passes through the electromagnetic field generated by the ion bar, and flows out from the upper outlet. The ion bar has a diameter and a length of 32 and $330 \mathrm{~mm}$, respectively. The metal pipe has a diameter of $100 \mathrm{~mm}$. The ion bar is connected to a high-voltage $\mathrm{AC}$ (Alternating Current) power source that provides $4 \mathrm{kV}, 50 \mathrm{~Hz}$ AC to create an alternating electric field around the ion bar. The direction and magnitude of the electric field strength change with time. The circulating cooling water flows between the ion bar and the metal tube wall, flows forward, and cuts the electric field lines.

According to our previous experiments using electrostatic fields, a voltage of $4 \mathrm{kV}$ may produce good scale inhibition effect. Therefore, six groups were set up: three experimental groups with AEFT and three control groups without AEFT.

\subsection{Preparation and Index Analysis of Circulating Cooling Water}

The influence of other factors was excluded in the experiment to accurately control the various indicators of water, and distilled water was used for the preparation of circulating cooling water. The conductivity of distilled water was approximately $4.0 \mu \mathrm{s} / \mathrm{cm}$. As shown in Table 1 for different groups, the quality of $\mathrm{CaCl}_{2}$ was the same in each group of experiments, and different masses of $\mathrm{MgCl}_{2}$ and $\mathrm{NaHCO}_{3}$ were added to the distilled water to prepare circulating cooling water. $\mathrm{CaCl}_{2}, \mathrm{NaHCO}_{3}$ and $\mathrm{MgCl}_{2}$ with corresponding masses were added to $250 \mathrm{~L}$ of distilled water. The circulating cooling water volume of each group was approximately $161 \mathrm{~L}$.

Table 1. Circulating cooling water quality index.

\begin{tabular}{ccccc}
\hline Group & AC Voltage & $\begin{array}{c}\mathbf{C a C l}_{\mathbf{2}} \\
(\mathbf{m m o l} / \mathbf{L})\end{array}$ & $\begin{array}{c}\mathbf{M g C l}_{\mathbf{2}} \\
(\mathbf{m m o l} / \mathbf{L})\end{array}$ & $\begin{array}{c}\mathbf{N a H C O}_{3} \\
(\mathbf{m m o l} / \mathbf{L})\end{array}$ \\
\hline 1 experimental group & $4 \mathrm{kV}$ & 12 & 0 & 12 \\
2 experimental group & $4 \mathrm{kV}$ & 12 & 4 & 16 \\
3 experimental group & $4 \mathrm{kV}$ & 12 & 6 & 18 \\
1 control group & No voltage & 12 & 0 & 12 \\
2 control group & No voltage & 12 & 4 & 16 \\
3 control group & No voltage & 12 & 6 & 18 \\
\hline
\end{tabular}

According to DL/T502.32-2006, the index of circulating cooling water sampled from the water intake in the experiment was analyzed. Calcium ions were determined by Ethylenediaminetetraacetic acid (EDTA) volumetric titration.

\subsection{Crystal Morphology and XRD Analysis of Scale Samples}

Scales have two kinds: those that attached to the inner wall of the copper tube of the counter flow heat exchanger called as call adherent scale, and those flowing with water in the circulating cooling water named as non-adherent scale. The adherent scale was scraped off with a nylon rod at the end of the experiments, and the non-adherent scale was collected in the experiment using a sieve with an aperture of $\leq 38 \mu \mathrm{m}$ installed in the water collecting tank. Both scales were dried at $105^{\circ} \mathrm{C}$ for more than $12 \mathrm{~h}$ after the end of the experiment, ground in an agate mortar, and placed in a dry bottle for storage.

Both scales were examined by scanning electron microscopy, and the non-adherent scale was analyzed by XRD. The X'Pert PRO-ray diffractometer produced by PANalytical was used in the XRD test. Jade software (version 6.0) was used for the analysis of the XRD results.

The mass fraction of aragonite and calcite was obtained by the following formula:

$$
W_{x}=\frac{I_{x}}{K_{A}^{X} \sum_{x=A}^{N} \frac{I_{x}}{K_{A}^{x}}}
$$


where $W_{X}$ is the mass fraction of the $X$ phase; $x$ is the $x$ th phase; $K_{A}^{X}$ indicates the $K$ value of the $X$ phase when $A$ is the internal standard; $I_{x}$ is the integral intensity of the $X$ phase; and $K_{A}^{x}$ is the $K$ value of the $x$ phase when $A$ is the internal standard. The $K$ values of aragonite and calcite were 1.13 and 3.15 , respectively.

\subsection{Average Scale Inhibition Rate Analysis}

According to the thermal equilibrium conditions of heat transfer theory, in a counter flow heat exchanger, the heat transfer coefficient $K$ is defined by the following formula:

$$
K=\frac{m_{c} C_{p c}\left(T_{c i}-T_{c o}\right) \ln \left(\frac{T_{h i}-T_{c o}}{T_{h o}-T_{c i}}\right)}{A\left[\left(T_{h i}-T_{c o}\right)-\left(T_{h o}-T_{c i}\right)\right]}
$$

where $T_{\mathrm{ci}}$ and $T_{\mathrm{co}}$ are the temperatures of the circulating cooling water inlet and outlet, respectively; $T_{h i}$ and $T_{h o}$ are the temperatures of the heated water inlet and outlet, respectively; $C_{p c}$ is the circulating cooling water constant pressure specific heat capacity; $m_{c}$ is the mass flow rate of circulating cooling water; and $A$ is the total heat exchange area of the heat exchanger.

Fouling resistance can be defined as follows:

$$
R_{t}=\frac{1}{K_{t}}-\frac{1}{K_{t=0}}
$$

where $R_{t}$ is the fouling resistance at any time; $K_{t}$ is the total heat transfer coefficient of the heat exchanger at any time; and $K_{t=0}$ is the total heat transfer coefficient of the heat exchanger at the initial time.

Based on the above formula, the scale inhibition rate can be defined as below and recorded by the computer every $10 \mathrm{~min}$.

$$
\eta_{t}=\left[1-\frac{R_{t, \text { experimental group }}(t)}{R_{t, \text { control group }}(t)}\right] \times 100 \%
$$

where $R_{t, \text { experimental group }}(t)$ is the fouling resistance of the experimental group; and $R_{t, \text { control group }}(t)$ is the fouling resistance of the control group.

Therefore, the average scale inhibition rate can be defined as follows:

$$
\eta_{\text {average }}=\frac{\sum_{\mathrm{i}=1}^{N} \eta_{t}}{N}
$$

\subsection{Scale Inhibition Rate Obtained by Mass Method}

The scale inhibition effect can also be reflected by the quality of the adherent scale attached to the inner wall of the copper tube. The formula for calculating scale inhibition using the mass method is as follows:

$$
\eta_{m}=\left(1-\frac{m_{e}}{m_{c}}\right) \times 100 \%
$$

where $m_{e}$ is the adherent scale quality of the experimental group; and $m_{\mathcal{C}}$ is the adherent scale quality of the control group.

\section{Results}

\subsection{Fouling Resistance Analysis}

The fouling resistance indicates the decrease in heat transfer efficiency due to deposits on the heat transfer surface of the heat exchange device, that is, the heat transfer resistance of the deposit on the heat transfer surface [2]. The real-time fouling resistance was calculated using Equations (2) and (3) and is shown in Figures 3 and 4. A time interval, which is called the initiation period or delay time, generally occurs from the start of the experiment to the detection of the fouling resistance [4]. 
However, no remarkable delay time was observed in this experiment due to the high hardness of the circulating cooling water.

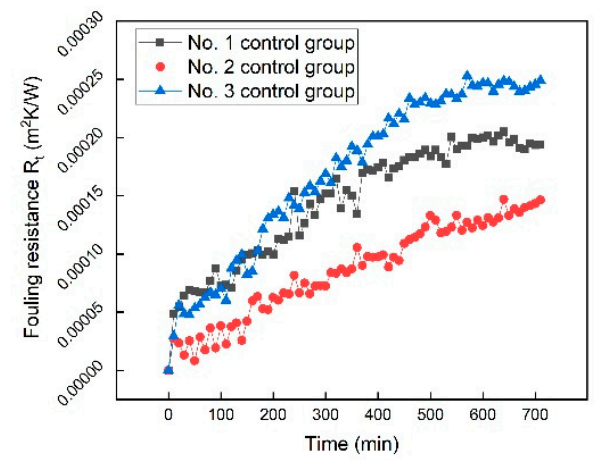

Figure 3. Real-time fouling resistance of control groups.

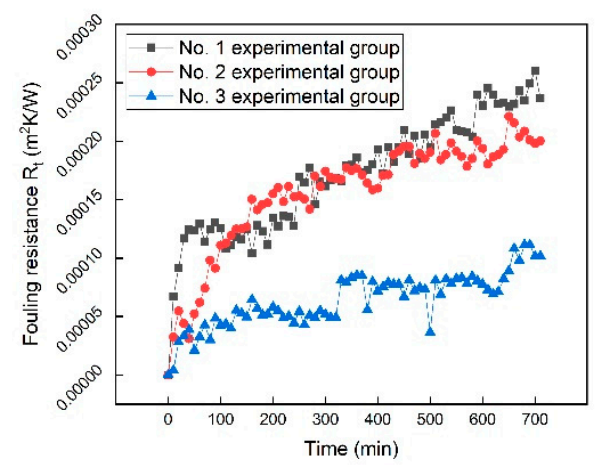

Figure 4. Real-time fouling resistance of experimental groups.

Magnesium ion concentration, as an important role, affects the fouling resistance. Figure 3 depicts that the fouling resistance of the control group changed and remarkably increased with time. The increase in No. 3 control group was significantly greater than that in the two other groups. Compared with that of No. 3 control group, the magnesium ion concentration of No. 2 control group inhibited the growth of the adherent scale. In the final stage, the fouling resistance curve tends to be gentle. This phenomenon occurred because the shearing force of the water transports some of the scales from the copper tube wall, and the quality of the subsequently formed scale is equivalent to the mass of the part that was removed. Hence, the two form a dynamic balance, and fouling resistance stops increasing.

Figure 4 depicts the change in the fouling resistance of the experimental groups with time. At the beginning of the experiment, the fouling resistance of the three experimental groups showed different degrees of decline. Jamialahmadi et al. [23] believed that this result occurs because the increase in the number of bubble nucleation sites during this time period affects the heat transfer coefficient near the heat exchanger until the sediment becomes the dominant heat transfer coefficient. No similar phenomenon was observed in the control group. Hence, AEFT was speculated to increase the bubble nucleation sites at the initial stage of the experiment. Compared with the control groups, the experimental groups exhibited fouling resistance at the beginning of the period for approximately 50-100 min at a low level and then increased significantly, indicating that AEFT can delay the fouling time. Xing [4] also observed a similar phenomenon in the study of electromagnetic field scale inhibition.

Although many studies confirmed that the high-frequency electric fields of suitable frequency have significant scale inhibition effects [2,10], the present experimental results showed that AEFT has a slight promoting effect on the formation of scale. For the three experimental groups with AEFT, the fouling resistance curves of Nos. 1 and 2 exhibited a large degree of coincidence. At the end of the experiment, the fouling resistance of No. 1 experimental group was $2.24 \times 10^{-4} \mathrm{~m}^{2} \mathrm{~K} / \mathrm{W}$, and that of No. 
1 control group was $1.99 \times 10^{-4} \mathrm{~m}^{2} \mathrm{~K} / \mathrm{W}$, exhibiting an increase of approximately $12.56 \%$. For No. 2 experimental group, the final fouling resistance was $2.00 \times 10^{-4} \mathrm{~m}^{2} \mathrm{~K} / \mathrm{W}$, and that of No. 2 control group was $1.53 \times 10^{-4} \mathrm{~m}^{2} \mathrm{~K} / \mathrm{W}$, exhibiting an increase of $30.71 \%$. In the case of constant magnesium ion concentration, the increase in fouling resistance indicated that AEFT has a certain promoting effect on the formation and growth of adherent scale. The fouling resistance of No. 2 experimental group was nearly twice that of No. 1 experimental group, indicating that the presence of magnesium ions at a concentration of $4 \mathrm{mmol} / \mathrm{L}$ enhanced the growth and adhesion of AEFT to the scale.

When the magnesium ion concentration was increased, the effect of AEFT on the fouling resistance was quite different. The final fouling resistance of No. 3 experimental group was $9.37 \times 10^{-3} \mathrm{~m}^{2} \mathrm{~K} / \mathrm{W}$, and that of No. 3 control group was $2.46 \times 10^{-4} \mathrm{~m}^{2} \mathrm{~K} / \mathrm{W}$, exhibiting a large reduction of $61.91 \%$. On the one hand, this result may be due to the fact that magnesium ions were easily attached to the kink sites of calcite crystals and acted to inhibit the growth of calcite crystals by acting as kink blockers [20]. On the other hand, magnesium ions changed the equilibrium thermodynamics of the new growth surface by incorporation into the calcium carbonate crystal lattice to inhibit the growth of calcite [19].

\subsection{Scale Inhibition Rate Analysis}

The effect of AEFT on the scale inhibition rate was nonlinear with the concentration of magnesium ions in the circulating cooling water. When the concentrations of magnesium chloride were 0 and $4 \mathrm{mmol} / \mathrm{L}$, the effect of promoting adherent scale formation was exhibited to a different extent, and the magnesium ion concentration showed a strong inhibitory effect when it was $6 \mathrm{mmol} / \mathrm{L}$. Table 2 shows the quality of the adherent scale, the mass scale inhibition rate $\eta_{m}$ obtained by Equation (6), and the average scale inhibition rate $\eta_{\text {average }}$ obtained by Equation (5). The differences in the quality of the adherent scale between Nos. 1, 2, and 3 experimental groups and Nos.1, 2, and 3 control groups were $0.19,2.08$, and $-0.61 \mathrm{~g}$, respectively. This finding indicated that AEFT exhibited different effects at different concentrations of magnesium ions. It further indicated that the AEFT in this experiment slightly promoted the growth of the adherent scale when the magnesium ion concentration was 0 $\mathrm{mmol} / \mathrm{L}$, which significantly promoted the adherent scale growth when magnesium ion concentration was $4 \mathrm{mmol} / \mathrm{L}$, and stronger inhibition of the adherent scale growth when magnesium ion concentration was $6 \mathrm{mmol} / \mathrm{L}$. The scale inhibition rate obtained by the mass method of Nos. 1 and 3 experimental groups were close to the average scale inhibition rate obtained by the fouling resistance method. However, a large gap was observed in the No. 2 experimental group, which may be due to accidental errors during weighing and the like. Therefore, the average scale inhibition rate obtained by the fouling resistance method was more reliable compared with.

Table 2. Adherent scale quality and scale inhibition rate.

\begin{tabular}{cccc}
\hline Group & Adherent Scale Quantity $\mathbf{( g )}$ & $\eta_{\boldsymbol{m}}(\mathbf{\%})$ & $\boldsymbol{\eta}_{\text {average }}(\mathbf{\%})$ \\
\hline 1 experimental group & 1.03 & -22.27 & -23.96 \\
2 experimental group & 2.60 & -403.09 & -107.86 \\
3 experimental group & 0.37 & 62.17 & 59.11 \\
1 control group & 0.84 & - & - \\
2 control group & 0.52 & - & - \\
3 control group & 0.98 & - & - \\
\hline
\end{tabular}

Real-time scale inhibition rate $\eta_{t}$ was obtained from Equation (4) and shown in Figure 5. The AEFT exhibited a great difference in the scale inhibition effects of the three experimental groups. The scale inhibition rate of No. 1 experimental group was relatively stable and always close to the position below the zero mark. The scale inhibition rate was negative most of the time, indicating that AEFT promotes the growth of adherent scale. The scale inhibition rate of the No. 3 experimental group was always kept above zero, and it remained basically stable without large fluctuations. 


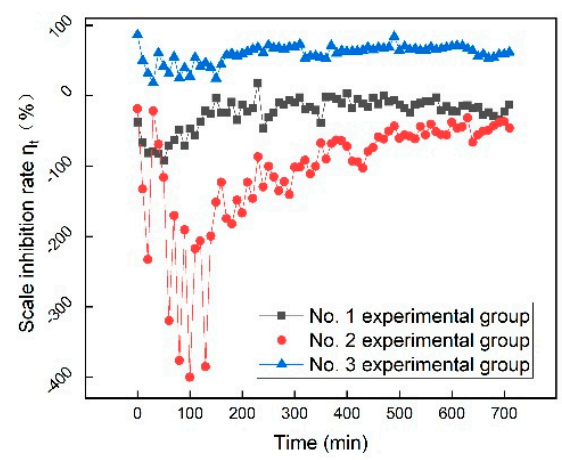

Figure 5. Real-time scale inhibition rate of experimental groups.

At the higher magnesium ion concentration of No. 3 experimental group, AEFT showed a significant inhibitory effect on the growth of the adherent scale. This finding indicates that a higher magnesium ion concentration is beneficial to the alternating electric field to better exert the scale inhibition effect. The average scale inhibition rate of the No. 1 experimental group was $-23.96 \%$, and that of the No. 2 experimental group was $-107.86 \%$. For the No. 2 experimental group, the generation of aragonite may be promoted under experimental conditions. The deposition of aragonite on the heat exchanger resulted in an increase in fouling resistance. Aragonite and calcite are two types of calcium carbonate crystals; on the surface of the heat exchanger, the aragonite is denser and firmer than the calcite deposit; hence, aragonite is more difficult to remove than the calcite [24]. An increase in aragonite was observed in the XRD result analysis and SEM photographs of the No. 2 experimental group. The average scale inhibition rate of the No. 3 experimental group was $59.11 \%$, which inhibited the formation of adherent scale and demonstrated a better scale inhibition effect.

In conclusion, when the magnesium ion concentration is relatively low, the alternating electric field promotes the growth of adherent scale. When the magnesium ion concentration is high, the alternating electric field will inhibit the growth of adherent scale. Therefore, the effect of the alternating electric field on the adherent scale depends on the concentration of magnesium ions in the circulating cooling water.

\subsection{Analysis of Changes in Calcium Ion Concentration}

The concentration of calcium ions is directly related to the formation of scale. The following reaction occurs in circulating cooling water:

$$
\mathrm{Ca}^{2+}+\mathrm{CO}_{3}^{2-} \leftrightarrow \mathrm{CaCO}_{3}
$$

To compensate for the loss of calcium ions in the circulating cooling water, $\mathrm{CaCl}_{2}$ was continuously added to the water, which led to an increase in the concentration of calcium ions with time. Within $2 \mathrm{~h}$ after the start of the experiment, given that the amount of calcium carbonate in the molecular state was less in water, the formation of calcium carbonate was fast, and the calcium ion concentration was remarkably lowered. Theoretically, the drug added to the circulating cooling water can produce $422 \mathrm{~g}$ of $\mathrm{CaCO}_{3}$, but the masses of the adherent scale and the non-adherent scale were far less than this value. Hence, most of the calcium carbonate still exists in the form of molecules and ions in the bulk water.

Electromagnetic fields can cause the calcium carbonate scale to grow in bulk water rather than on the walls of heat exchangers by increasing the probability of collision between ions $[3,16,17]$. We found that magnesium ions have a certain effect on the effect of AEFT. A high concentration of magnesium ions favors AEFT to promote calcium carbonate, which grows in a large amount of water rather than on the heat exchanger wall. Figure 6 shows the changes in calcium ion concentration over time in the three experimental groups. The calcium ion concentration in the experimental group decreased the fastest in the first $2 \mathrm{~h}$. A high magnesium ion concentration leads to a fast rate of decline. After $2 \mathrm{~h}$, the effect of the tonic system began to appear when the scaling rate decreased. The addition of calcium chloride continuously increased the calcium ion concentration in the water. At the end of the 
experiment, the change in the calcium ion concentration was $27.1 \%$ in the No. 1 experimental group, $16.3 \%$ in the No. 2 experimental group, and $-0.6 \%$ in the No. 3 experimental group. The group with high magnesium ion concentration has less calcium ion content at the end of the experiment, indicating that plenty of molecular forms of calcium carbonate were found in the experimental group with high magnesium ion. Table 3 shows the quality of non-adhesive scale. Therefore, many calcium carbonate molecules were intercepted in the No. 3 experimental group, and the quality of the scale of this group was significantly higher than that of the other experimental groups.

Table 3. Non-adherent quality.

\begin{tabular}{cc}
\hline Group & Non-Adherent Scale (g) \\
\hline 1 experimental group & 27.80 \\
2 experimental group & 25.21 \\
3 experimental group & 32.39 \\
1 control group & 31.53 \\
2 control group & 36.93 \\
3 control group & 20.39 \\
\hline
\end{tabular}

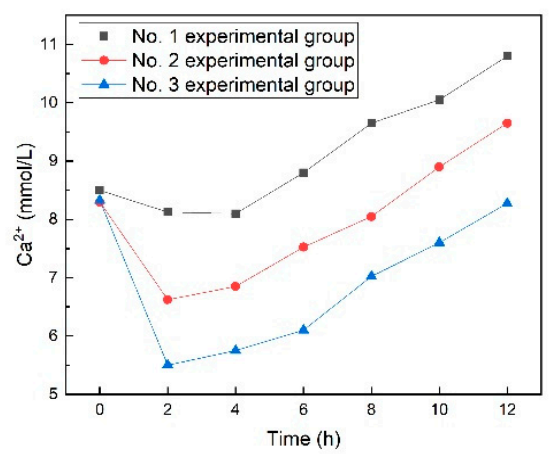

Figure 6. Experimental groups calcium ion concentration.

\subsection{Component Analysis of Calcium Carbonate Scale Samples}

The three types of calcium carbonate crystals are aragonite, calcite, and vaterite. Among them, calcite scaling is the most stable, aragonite is a high-pressure crystal, and vaterite has unstable thermodynamic properties [2]. In this experiment, we found two types of calcium carbonate, aragonite and calcite, in the XRD results of non-adherent scale samples and calculated the relative mass fraction. The adherent scale attached to the pipe wall cannot be easily scraped and has a small quantity. The non-adherent scale intercepted by the sieve in the water collecting tank was easy to collect. Hence, the non-adherent scale was conducted by XRD analysis.

The non-adherent components of the experimental groups are shown in Table 4. Among the six groups of non-adherent scales, the largest difference in the relative content of aragonite and calcite was observed in the No. 2 experimental group, and the other groups exhibited only slight differences. In heat exchangers, aragonite tends to become dense, is highly adherent and scale-removing, whereas the calcite is granular, with poor adhesion, and is easily mobilized by the shearing force of flowing water [3,4]. The high content of aragonite in non-adherent indicates that the aragonite has a great chance of adhering to the copper tube wall of the heat exchanger. Many aragonite feature structures were also observed on the SEM photograph of the scale of the No. 2 experimental group. 
Table 4. Non-adherent scale mass fraction.

\begin{tabular}{ccc}
\hline Group & Aragonite (\%) & Calcite (\%) \\
\hline 1 experimental group & $4.78 \%$ & $95.22 \%$ \\
2 experimental group & $20.76 \%$ & $79.24 \%$ \\
3 experimental group & $4.52 \%$ & $95.48 \%$ \\
1 control group & $2.45 \%$ & $97.55 \%$ \\
2 control group & $4.78 \%$ & $95.22 \%$ \\
3 control group & $3.20 \%$ & $96.80 \%$ \\
\hline
\end{tabular}

Nielsen et al. [20] believed that high concentrations of magnesium ions inhibit the growth of calcite, and a similar phenomenon was observed in the non-adherent scale of the heat exchanger of the control group. Compared with the No. 1 control group, the No. 2 and No. 3 control groups with magnesium ions added have lower calcite content and higher aragonite content. This may be that during the growth of calcite, magnesium ions are more likely to adhere to its growth surface. Thereby, magnesium ion enters the lattice structure of calcite and occupies the original position of calcium ions in the calcite lattice to inhibit the continuous growth of calcite crystals [19,20]. For the No. 2 experimental group, this effect is significantly enhanced under the action of high-voltage electric field. However, there is no similar effect on aragonite.

\subsection{Crystal Morphological Analysis of Calcium Carbonate Scale Samples}

Figures 7 and 8 show the SEM photographs in 5000× magnification of the adherent and non-adherent scales in the experimental group and control group, respectively. Aragonite is a needle-like structure, and calcite is mainly a cubic block structure.
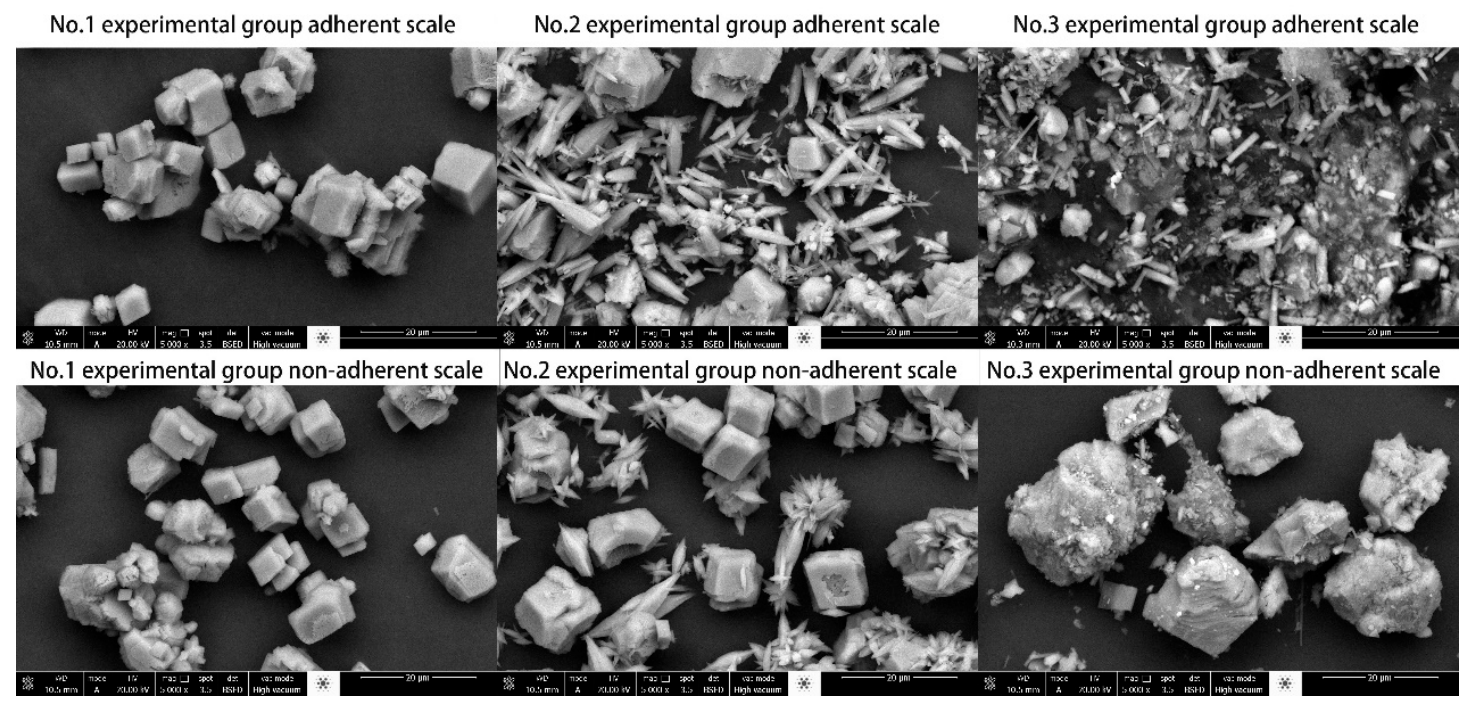

Figure 7. Experimental groups SEM photos. 

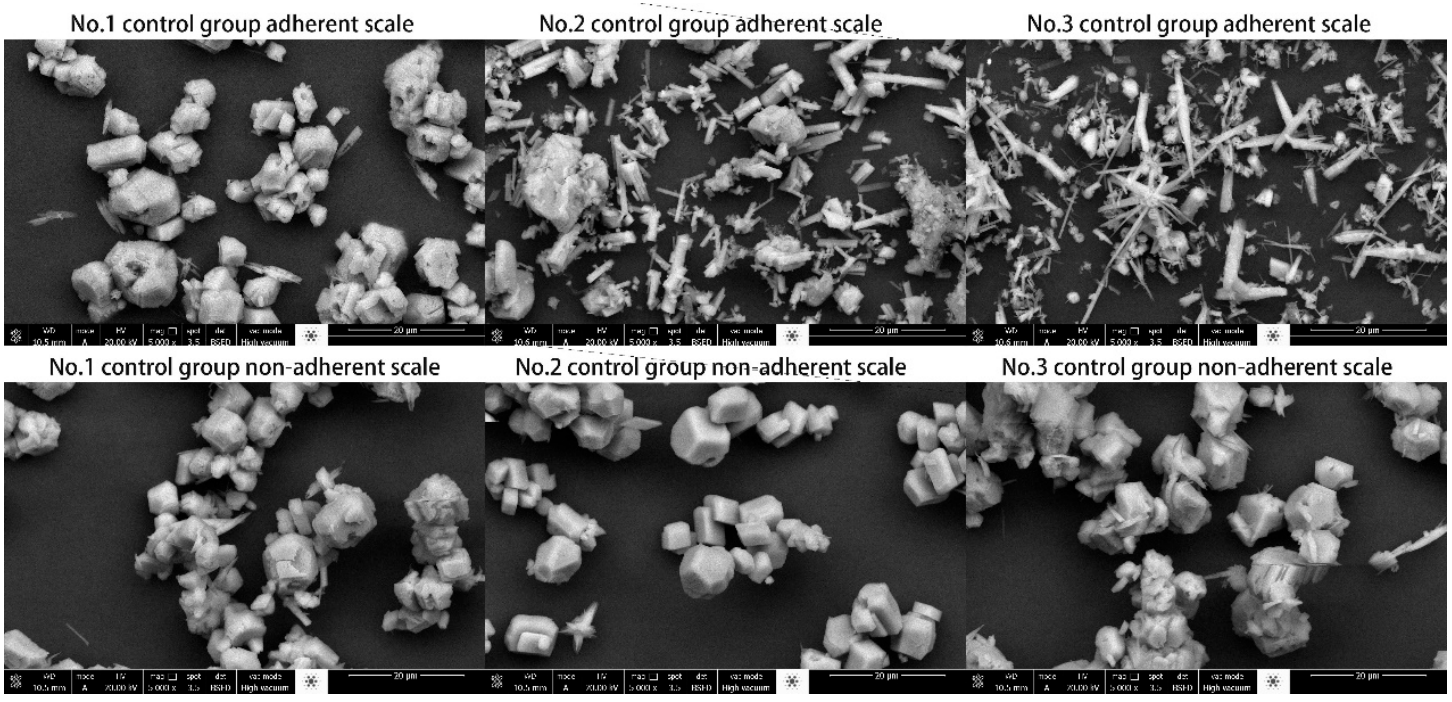

Figure 8. Control groups SEM photos.

Magnesium ions have a significant effect on the morphology of the adherent scale. The presence of magnesium ions promotes a proportional increase in aragonite in the adherent scale. The non-adherent scale of the control group was still dominated by a cubic block calcite structure. In the control groups, a large number of rod-like crystal structures appeared in the adherent scales of Nos. 2 and 3 control groups, especially in that of the No. 3 control group, which was closer to the needle-like structure.

AEFT showed a different effect on the crystal morphology for different magnesium ion concentrations. In the non-adherent scale of the experimental group, No. 1 experimental group showed no significant change compared with the control group, and a certain proportion of needle-like structure appeared in No. 2 experimental group, indicating that the proportion of aragonite increased, which was also verified by XRD analysis. The grain size of No. 3 was increased compared with that of the control group. For the adherent scale of the experimental groups, the crystal structure of No. 1 experimental group was closer to the cube than that of No. 1 control group, which increased the contact area with the inner wall of the heat exchanger and led to the easier adhesion to the inner wall of the heat exchanger to continue to grow, resulting in an increase in fouling resistance. This phenomenon explains the negative rate of the scale inhibition rate of the No. 1 experimental group. The needle-like aragonite structure in the scale of the No. 2 experimental group has a larger proportion, and the cubic block-like calcite structure has lesser proportion. The crystal structure of the No. 2 experimental group is more compact than that of the No. 2 control group. Given that the ability of aragonite to adhere to the heat exchanger wall was stronger than that of calcite, the fouling resistance of the No. 2 experimental group was considerably larger than that of the No. 2 control group. For the adherent scale of the No. 3 experimental group, the crystal particles became significantly smaller, and the rod-shaped crystal structure showed a rounded shape at both ends. The crystals were loosely bonded and were more easily washed away by running water, which made attaching and growing on the heat exchanger tube wall difficult; hence, the fouling resistance was significantly reduced compared with that of the No. 3 control group.

\section{Conclusions}

The following conclusions were obtained in this experiment:

1. The concentration of magnesium ions in circulating cooling water is one of the factors affecting the fouling resistance of heat exchangers.

2. The scale inhibition effect of AEFT is nonlinearly related to the concentration of magnesium ions in water. In the absence of magnesium ions, AEFT plays a relatively weak role in promoting 
the growth of adherent scale. When the concentration of magnesium chloride was $4 \mathrm{mmol} / \mathrm{L}$, the electric field exhibited a strong promoting effect on the growth of the adherent scale. When the concentration was $6 \mathrm{mmol} / \mathrm{L}$, AEFT exhibited a remarkable inhibitory effect on the growth of the adherent scale.

3. When the SEM photograph was magnified $5000 \times$ for each group of scales, the crystal morphology in the adherent scale and non-adherent scale was mainly calcite in the absence of magnesium ions. When magnesium ion was present, the aragonite crystal morphology of the scale was significantly increased. When the concentration of magnesium chloride was $6 \mathrm{mmol} / \mathrm{L}$ and AEFT was present, the adherent scale grains were smaller than other cases, and the structure became loose.

Author Contributions: Z.Z. completed the experiment and the writing of the first draft of the article, and Y.J. participated in the analysis of the data and the related experimental process. J.Z. guided and supervised the experiment. All of us participated in the experiment design and planning process. All authors have read and agreed to the published version of the manuscript.

Funding: This research was funded by National Natural Science Foundations of China. (No. 61761036).

Acknowledgments: The authors would like to express their gratitude to the anonymous referees for their valuable comments and suggestions.

Conflicts of Interest: The authors declare no conflict of interest.

\section{References}

1. Tijing, L.D.; Pak, B.C.; Lee, D.H.; Cho, Y.I. Heat-treated titanium balls for the mitigation of mineral fouling in heat exchangers. Exp. Heat Transf. 2008, 21, 115-132. [CrossRef]

2. Tijing, L.D.; Lee, D.H.; Kim, D.W.; Cho, Y.I.; Kim, C.S. Effect of high-frequency electric fields on calcium carbonate scaling. Desalination 2011, 279, 47-53. [CrossRef]

3. Tijing, L.D.; Kim, H.Y.; Lee, D.H.; Kim, C.S.; Cho, Y.I. Use of an Oscillating Electric Field to Mitigate Mineral Fouling in a Heat Exchanger. Exp. Heat Transf. 2009, 22, 257-270. [CrossRef]

4. Xing, X. Research on the electromagnetic anti-fouling technology for heat transfer enhancement. Appl. Therm. Eng. 2008, 28, 889-894.

5. Yang, Q.F.; Liu, Y.Q.; Gu, A.Z.; Ding, J.; Shen, Z.Q. Investigation of induction period and morphology of CaCO3 fouling on heated surface. Chem. Eng. Sci. 2002, 57, 921-931. [CrossRef]

6. Zhao, J.D.; Liu, Z.A.; Zhao, E.J. Combined effect of constant high voltage electrostatic field and variable frequency pulsed electromagnetic field on the morphology of calcium carbonate scale in circulating cooling water systems. Water Sci. Technol. 2014, 70, 1074-1082. [CrossRef]

7. Liu, B.; Li, G.; Li, Y.; Sun, H.; Cheng, A.; Jia, W. Experimental Study on Magnetic Induction Properties of PVC Pipe in Electronic Anti-Fouling Technology. Pol. J. Environ. Stud. 2019, 28, 205-211. [CrossRef]

8. Alimi, F.; Tlili, M.; Amor, M.B.; Gabrielli, C.; Maurin, G. Influence of magnetic field on calcium carbonate precipitation. Desalination 2007, 206, 163-168. [CrossRef]

9. Tijing, L.D.; Yu, M.H.; Kim, C.H.; Amarjargal, A.; Lee, Y.C.; Lee, D.H.; Kim, D.W.; Kim, C.S. Mitigation of scaling in heat exchangers by physical water treatment using zinc and tourmaline. Appl. Therm. Eng. 2011, 31, 2025-2031. [CrossRef]

10. Wang, J.G.; Liang, Y.D. Anti-fouling effect of axial alternating electromagnetic field on calcium carbonate fouling in U-shaped circulating cooling water heat exchange tube. Int. J. Heat Mass Transf. 2017, 115, 774-781. [CrossRef]

11. Wang, X.L.; Zhao, J.D.; Liu, Z.A.; Zhao, E.J.; Yang, X.; Shao, X.J. Effect on the calcium carbonate scale in circulating cooling water: Constant magnetic and pulsed magnetic fields. Desalin. Water Treat. 2018, 124, 125-133. [CrossRef]

12. Al Nasser, W.N.; Al Ruwaie, A.H.; Hounslow, M.J.; Salman, A.D. Influence of electronic antifouling on agglomeration of calcium carbonate. Powder Technol. 2011, 206, 201-207. [CrossRef]

13. Han, Y.; Zhang, C.; Zhu, L.; Gao, Q.; Wu, L.; Zhang, Q.; Zhao, R. Effect of alternating electromagnetic field and ultrasonic on $\mathrm{CaCO} 3$ scale inhibitive performance of EDTMPS. J. Taiwan Inst. Chem. Eng. 2019, 99, 104-112. [CrossRef] 
14. Piyadasa, C.; Yeager, T.R.; Gray, S.R.; Stewart, M.B.; Ridgway, H.F.; Pelekani, C.; Orbell, J.D. The influence of electromagnetic fields from two commercially available water-treatment devices on calcium carbonate precipitation. Environ. Sci. Water Res. Technol. 2017, 3, 566-572. [CrossRef]

15. Kobe, S.; Dražić, G.; Cefalas, A.C.; Sarantopoulou, E.; Stražišar, J. Nucleation and crystallization of CaCO3 in applied magnetic fields. Cryst. Eng. 2002, 5, 243-253. [CrossRef]

16. Cho, Y.I.; Fridman, A.F.; Lee, S.H.; Kim, W.K. Physical water treatment for fouling prevention in heat exchangers. Adv. Heat Transf. 2004, 38, 1-72.

17. Gabrielli, C.; Jaouhari, R.; Maurin, G.; Keddam, M. Magnetic water treatment for scale prevention. Water Res. 2001, 35, 3249-3259.

18. Shahryari, A.; Pakshir, M. Influence of a modulated electromagnetic field on fouling in a double-pipe heat exchanger. J. Mater. Process. Technol. 2008, 203, 389-395. [CrossRef]

19. Davis, K.J.; Dove, P.M.; De Yoreo, J.J. The role of $\mathrm{Mg}^{2+}$ as an impurity in calcite growth. Science 2000, 290, 1134-1137. [CrossRef]

20. Nielsen, L.C.; De Yoreo, J.J.; DePaolo, D.J. General model for calcite growth kinetics in the presence of impurity ions. Geochim. Et Cosmochim. Acta 2013, 115, 100-114. [CrossRef]

21. Zhang, Y.P.; Dawe, R.A. Influence of $\mathrm{Mg}^{2+}$ on the kinetics of calcite precipitation and calcite crystal morphology. Chem. Geol. 2000, 163, 129-138. [CrossRef]

22. Kazi, S.N.; Duffy, G.G.; Chen, X.D. Mineral scale formation and mitigation on metals and a polymeric heat exchanger surface. Appl. Therm. Eng. 2010, 30, 2236-2242. [CrossRef]

23. Jamialahmadi, M.; Blöchl, R.; Müller-Steinhagen, H. Bubble dynamics and scale formation during boiling of aqueous calcium sulphate solutions. Chem. Eng. Process. Process. Intensif. 1989, 26, 15-26. [CrossRef]

24. Cho, Y.I.; Fan, C.F.; Choi, B.G. Theory of electronic anti-fouling technology to control precipitation fouling in heat exchangers. Int. Commun. Heat Mass Transf. 1997, 24, 757-770. [CrossRef]

(C) 2020 by the authors. Licensee MDPI, Basel, Switzerland. This article is an open access article distributed under the terms and conditions of the Creative Commons Attribution (CC BY) license (http://creativecommons.org/licenses/by/4.0/). 